ROCZNIKI HUMANISTYCZNE

Tom LXVIII, zeszyt $10 \quad-\quad 2020$

DOI: http://dx.doi.org/10.18290/rh206810-10

ALEKSY KUCY

ZOJA KUCA

\title{
ИЗБРАННЫЕ АСПЕКТЫ ТЕОРИИ И ПРАКТИКИ \\ ПРЕПОДАВАНИЯ АУДИОВИЗУАЛЬНОГО ПЕРЕВОДА НА ПОЛЬСКИХ НЕОФИЛОЛОГИЧЕСКИХ НАПРАВЛЕНИЯХ
}

Аудиовизуальный перевод, или AVT (анг. audiovisual translation), в англоязычной и русскоязычной литературе уже давно получил статус отдельного вида перевода и даже сформировавшейся академической дисциплины. В Польше настоящая отрасль переводоведения представлена, в частности, трудами таких исследователей как Агнешка ПалионМусиол, Малгожата Триюк, Кшиштоф Лоска, Тереза Томашкевич, Марек Хендриковски, Ивона Сикора и другие. Среди русскоязычных исследователей внимание заслуживают такие ученые как Вера Горшкова, Наталья Корнаухова, Алексей Козуляев, Игорь Сапожников и другие лингвисты, чьи монографии, краткие очерки или статьи в большей или меньшей степени рассматривают данную проблематику.

Что же касается англоязычных авторов, то в последнее время одним из авторитетных ученых, ведущих свои изыскания в сфере AVT, является Ив Гамбье - французский лингвист и почетный профессор пись-

Д-р Зоя КуцА - Лодзинский университет, Институт русистики, Кафедра языковедения; эл. адрес: zoja.kuca@uni.lodz.pl. ORCID: 0000-0003-2194-9250.

Д-р наук АлЕКсей Куций - Лодзинский университет, Институт русистики, Кафедра языковедения; эл. адрес: aleksy.kucy@uni.lodz.pl. ORCID 0000-0001-6655-6886.

Dr ZoJa KuCA - Uniwersytet Łódzki, Instytut Rusycystyki, Zakład Językoznawstwa; e-mail: zoja.kuca@uni.lodz.pl. ORCID: 0000-0003-2194-9250.

Dr hab. Aleksy KuCY - Uniwersytet Łódzki, Instytut Rusycystyki, Zakład Językoznawstwa; e-mail: aleksy.kucy@uni.lodz.pl. ORCID 0000-0001-6655-6886.

Zoya KuCA, PhD - University of Lodz, Institute of Russian Studies, Department of Linguistics; e-mail: zoja.kuca@uni.lodz.pl. ORCID: 0000-0003-2194-9250.

Dr. habil. AleXey KuCY - University of Lodz, Institute of Russian Studies, Department of Linguistics; e-mail: aleksy.kucy@uni.lodz.pl. ORCID 0000-0001-6655-6886. 
менного и устного перевода из Университета Турку ${ }^{1}$. Гамбье разработал хронологически-исторический базис развития аудиовизуального перевода и выделил ряд специфических характеристик, отличающих его от других видов перевода, в том числе, рассмотрел вопросы методологического характера.

Кристофер Тейлор является еще одним, на этот раз из Италии, если можно так выразиться, классиком теоретических изысканий интересующей нас области ${ }^{2}$ В качестве отправной точки своих исследований он использует понятие мультимодальности, или совокупности нескольких семиотических модулей, - ключевого атрибута в процессе создания любого семиотического продукта, такого как фильм, телевизионные программы, веб-сайты и т.д. Мультимедийный продукт Тейлор относит к сфере так называемых архетипических мультимодальных текстов. Ученый сознательно прибегает к положению модальности, поскольку считает данную перспективу главным определяющим фактором в аудиовизуальном переводе, который, по его мнению, кардинально отличается от всех других видов перевода в связи с задействованием в нем огромного числа вербальных и невербальных элементов.

Starting from the assumption that speech or writing cannot 'say' everything, it is the interaction between word, image, sound, etc. that needs to be studied. This interaction between verbal ele-ments, traditionally the object of translation studies, and the visual, acoustic, kinetic and other semiotic modes.

Именно такая задача, по мнению Тейлора, стоит перед любым аудиовизуальным переводчиком (Taylor 99-100).

Так или иначе, на сегодняшний день одной из основных тенденций в научном анализе AVT является его привязка к кинематографической продукции. Возможно, это вызвано фактом развития данного вида перевода в рамках коммерческого рынка кинематографа, который прошел эволюцию от немого кино с начала XX века вплоть до нынешнего 3Dвидеоряда. Отсюда, в основном, все теоретики в своих анализах сосредоточиваются именно на кинопродукции, упуская из виду такую интересную область перевода, как компьютерные видеоигры. Небезызвестно, что геймерская (отангл. gamer) отрасль по своим масштабам ничуть

\footnotetext{
${ }^{1}$ См. веб-страничку ученого в Университете в Турку: https://research.utu.fi/converis/ portal/Person/976336? aux fun=\&lang=en_GB, доступ 03.10.2019.

${ }^{2}$ См. веб-страничку ученого в Университете Триеста: https://iuslit.units.it/en/node/1532, доступ 03.10.2019.
} 
не уступает кинопродукции, заняв прочную позицию востребованности в современном цифровом социуме: сегодня рынок переводов геймерской продукции только набирает свои обороты.

Тереза Томашкевич сосредотачивает свое внимание на междисциплинарном характере аудиовизуального перевода и утверждает, что AVT представляет собой смешение двух видов перевода, представленных еще Романом Якобсоном - межъязыкового и интерсемиотического (Jakobson 232-239).

Do tego dochodzą nowe formy zaliczane do thumaczenia audiowizualnego: podpisy dla niesłyszących i audiodeskrypcja oddająca za pomocą form językowych to, co jest widoczne na ekranie z przeznaczeniem dla osób niewidzących. W pierwszym przypadku mamy do czynienia $\mathrm{z}$ formą tłumaczenia wewnątrzjęzykowego, a w drugim intersemiotycznego. (Tomaszkiewicz, «Przekład audiowizualny» 41).

Томашкевич обращает внимание также на то, что многие исследователи AVT забывают о фундаментальной концепции построения автором смысла текста, который сочетает словесные и визуальные элементы, что образ имеет универсальное значение и не ориентирован только на семиотику.

Zbyt dużo prac z dziedziny przekładu audiowizualnego pomija absolutnie wymiar wizualny tych produkcji, zajmując się tylko i wyłącznie technikami transferu językowego. Dzieje się tak dlatego, że wielu językoznawców czy translatoryków $\mathrm{z}$ definicji nie zajmuje się semiologią szeroko rozumianą. Otóż myślę, że coraz trudniej wyobrazić sobie badania nad komunikacją z pominięciem wymiaru niejęzykowego. (Tomaszkiewicz, «Przekład audiowizualny» 43).

Тем не менее большинство исследователей сходятся во мнении касательно основных видов AVT. На первом месте находится субтитрирование и дубляж. Затем, согласно рейтингу популярности, идет закадровый перевод, телетекст, синхронный перевод, надписи, повествование и аудиоописание. Закадровый перевод или так называемый войсовер (анг. voice over) особенно популярен в Польше в отношении аудиовизуального перевода документальных фильмов, популярных и популярно-научных передач, транслируемых западноевропейскими телевизионными каналами. Хотя в отношении этого вида перевода Марек Хендриковски утверждает, что он искажает исходный видеоряд:

Immanentna niedoskonałość wersji lektorskiej uwidacznia się szczególnie wyraźnie w praktycznym jej zetknięciu z tymi filmami, których kompozycja dźwię- 
kowa współtworzy istotną wartość artystyczną. Pośrednictwo lektora, nawet najbardziej subtelne i neutralne, okalecza w takich wypadkach pierwowzór, pozbawiając go wielu istotnych wartości. (Hendrykowski 274)

Нельзя не согласиться с таким утверждением, особенно если мы примем во внимание тот факт, что AVT транслируется по трём семиотическим уровням восприятия информации: вербальном, визуальном и аудиальном. Может быть, именно поэтому в польской киноиндустрии, ориентированной на молодого пользователя, в частности, в мультипликационных фильмах, в качестве преобладающего переводческого инструмента используется именно дубляж, а не войсовер.

Если же речь идет о дублировании, то в нем, по мнению Фредерика Хауме, выделяются три главных типа синхронизации: фонетическую (синхронизация контента с пластикой губ и мимикой задействованных актеров), кинетическую (синхронизация контента с текущим движением) и временную (учет временных интервалов в потоке сюжетной информации) (Chaume 43). В отношении явления синхронизации Хауме дает такое определение:

Synchronization is one of the features of translation for dubbing, which consists of matching the target language translation and the articulatory and body movements of the screen actors and actresses, as well a matching the utterances and pauses in the translation and those of the source text. (Chaume 43)

То есть, по мнению исследователя, с переводческой точки зрения процесс синхронизации заключается в том, чтобы записывать на переводящем языке оригинальные диалоги и монологи таким образом, чтобы новому тексту в максимальной степени соответствовали жестикуляция и мимика персонажей, отображаемых на экране. В этом процессе, по мнению большинства ученых, основное внимание обращается на необходимость синхронизации переводящего контента с движениями губ. Отсюда качество и адекватность перевода, которые в случае дубляжа так или иначе зависят от уровня осуществления вышеопределенных синхронизмов, часто обусловлено необходимостью видоизменения исходного содержания текста, т.е. формального отступления от оригинала.

Возвращаясь к классификации видов аудиовизуального перевода, можно утверждать, что ее наиболее полный вариант представлен на сегодняшний день все тем же профессором Гамбье. Перечислим предложенные им варианты межъязыкового перевода. Итак, согласно выше- 
упомянутой классификации, говоря о межъязыковой AVT, стоит учитывать его главные виды:

а) перевод сценариев (анг. script/scenario translation). Данный вид перевода используется на начальной стадии разработки медиального продукта. В частности, он необходим для привлечения финансирования нового проекта;

б) межъязыковое субтитрирование (анг. interlingual subtitling), то есть один из наиболее распространенных видов перевода AVT, добавляющий к киноленте новый семиотический канал информации;

в) дубляж с синхронизацией звукоряда (анг. dubbing) (Gambier 50-51).

Существуют также и другие виды перевода AVT, однако мы не будем сейчас на них останавливаться подробно. Стоит лишь упомянуть о том, что в различных типах AVT используются различные стратегии и техники перевода. В одних на первый план выдвигается звуковая передача информации, в частности, в дублировании, устном переводе, озвучивании и свободном комментарии. В других, - происходит переход от устного перевода к письменному: межъязыковому, внутриязыковому, прямым субтитрам и обычным субтитрам. Речь идет также о восхождении от письменного к письменному, например, в случае перевода сценариев, или же письменного к устному: визуальный перевод, аудиосубтитры - $\mathrm{LRC}^{3}$, используемые, как правило, для просмотра таймированных текстов песен на языке оригинала. В связи с этим Гамбье ставит задачу поиска ответа на следующий вопрос:

This raises the interesting question of whether we can say that certain types of AVT are more domesticating modes of translation than others. It is true that dubbing, free commentary, even interpreting and audio description, allow the manipulation of the linguistic material in order to please dominant expectations and preferences, sometimes censoring dialogues or changing parts of the plot to conform to target culture ideological drives and aesthetic norms. (Gambier 51-52)

Ответ, по мнению исследователя, кроется в истории AVT, которая проливает свет на использование всех типов аудиовизуального перевода как инструментов языкового протекционизма и языкового пуризма, нарушая в определенной степени этические принципы, стирая следы „Другого” - включая его голос и речь. Нельзя не согласиться с этим мнением, однако, как признается сам автор высказывания, мощная роль AVT основана не только на такой ассимиляции или подчиненности, но

\footnotetext{
${ }^{3}$ Формат хранения текста песни (от анг. Lyrics).
} 
и на решении проблем международной дистрибуции, раскрытия культур друг другу и широкого распространения аудиовизуальной продукции, что, конечно же, не может обойтись без ряда сложных проблем.

Рассматривая дублирование в полном объеме как явление, необходимо обратить внимание на широкий масштаб организационных и технических мероприятий, необходимых в процессе подготовки финального продукта. В отличие от субтитрирования, в дубляже задействован целый ряд специалистов и самое современное компьютерное и цифровое оборудование. Кроме подготовки переводящего контента, за который отвечает переводчик, в этом процессе задействованы также информатики программисты, звукорежиссер, а также специалисты в области видеоизображения. Этот момент очень часто упускается из виду теоретиками AVT, но именно он, на наш взгляд, делает дублирование одним из наиболее сложных и одновременно увлекательных видов перевода.

Рассматривая вопросы, связанные с субтитрированием, необходимо отметить значение повышающегося уровня технологического прогресса в целом. Сегодня компьютер как атрибут любой домашней атмосферы, a также доступность большого количества специализированных программ, делают возможным „игру” в переводчика для любого пользователя, обладающего относительно высоким уровнем знания иностранного языка. Нашу первую презентацию на занятиях по аудиовизуальному переводу мы уже несколько лет подряд начинаем с темы: „Фансабберы, - это мы?". Настоящее определение связано с английским понятием fansub, происходящим от сокращения слов fan subtitles, т.е. любительские субтитры. В связи с распространением упрощенных систем видеоредактирования и Интернета, создание, редактирование и распространение субтитров значительно упростилось. По всему миру начали появляться так называемые фансабб-группы, иными словами общества переводчиков, занимающихся домашним субтитрированием, созданием цифрового фансабба. Насколько качество таких субтитров соответствует языковым и техническим нормам, а также наполнено адекватностью, вопрос второстепенный. Натали Корнаухова замечает другую деталь, а именно, что в этом явлении

мы сталкиваемся с появлением одновременно двух и более версий перевода одного и того же аудиовизуального материала от разных релиз-групп, которые все стремительнее отвоевывают себе пространство на просторах интернета, практически безраздельно доминируя в переводе сериалов. (Корнаухова 113) 
Такая практика перевода AVT, по мнению исследовательницы, не только меняет наше представление об аудиовизуальном переводе, но и сам его процесс, который претерпевает изменения с точки зрения этики, переводческих норм и переводческой дидактики.

Это явление вызвано также эволюцией самих субтитров, а именно, появлением так называемых мягких субтитров, анг. soft subtitles - самых распространенных вследствие легкости их составления и больших возможностей при оформлении. Нужно отметить, что данный вид субтитров относится к одному из последних видов, которому предшествовали такие субтитры как hard subtitles, т.е. жесткие субтитры, не представляющие собой отдельного файла, в отличие от мягких, а встроенные в видеоряд на постоянной основе. В настоящем случае изображение с текстом субтитров накладывалось на исходное видео в процессе создания итогового файла, - видеомонтажа, после выполнения которого внесение изменений в текст перевода уже не представлялось возможным. Должно быть, именно из-за этого жесткие субтитры уже практически не встречаются. И, в конечном счете, последний, промежуточный вид субтитров - prerendered subtitles, которые на русском языке можно охарактеризовать как предварительно отображенные. Данные субтитры представлены в виде изображения, хранящегося отдельно от существующего видеофайла. Их суть заключается в том, что, несмотря на то, что они встроены в видеоряд, их все же можно экстрагировать из основного видеофайла и внести необходимые изменения. Для этого, однако, потребуется процедура их преобразования в мягкий формат, например, в наиболее популярный среди мягких субтитров - SRT (анг. SubRip file format).

В настоящей статье мы не можем описать все виды аудиовизуального перевода, а также всех сложностей и нюансов, связанных с осуществлением AVT, в частности, описать технические и языковые требования к отдельным видам перевода. Нашей главной задачей является обсуждение, с одной стороны, влияния преподавания AVT на неофилологических направлениях на языковую компетенцию студентов, а с другой, - развитие дополнительных навыков и умений, необходимых в процессе освоения иностранного языка.

Технологический прогресс и появление новых форм AVT, к примеру, описанного фансаббинга, а также других видов „домашнего перевода” не может не отражаться на дидактике аудиовизуального перевода. В процессе обучения аудиовизуальному переводу Гамбье выделяет ряд 
требуемых компетенций, свойственных только этому виду перевода, которые необходимо воспитывать у учащихся. Обратим внимание на некоторые из них. Итак, это умение анализировать потребности целевой аудитории; способность соотносить вербальную и визуальную составляющую контента; способность к межличностному сотрудничеству и командной работе; способность выражать мысль кратко и чувствовать ритм высказывания, ритм смены образов, ритм чтения титров, определяемый кадром и аудиторией; умение адаптироваться к новым инструментам и знакомиться с ними (Gambier 55). В качестве дидактической основы в преподавании аудиовизуального перевода исследователь рекомендует программу обучения журналистов, поскольку переводчику AVT необходимы схожие навыки: навык создания письменных и устных текстов, способность к осознанию широкой социокультурной значимости деятельности, выходящей за рамки написания текста, способность выбора стратегии поиска информации, навык работы с людьми и т.д. (Gambier 55).

Исходя из нашего опыта в преподавании аудиовизуального перевода на неофилологических направлениях, можно констатировать, что представленный выше список умений и требования профессора Гамбье к переводчику AVT далеко не исчерпывает исследуемой проблематики. Применение описанных рекомендаций вполне подойдет к преподаванию субтитрирования, письменного перевода сценариев и другого мультимедийного контента, однако в случае присутствия в научно-дидактической программе дубляжа, синхронного перевода и озвучивания в виде свободного комментирования, потребуется формирование дополнительных навыков - более сложных и продвинутых по своему внутреннему содержанию.

Итак, описывая польский опыт в обучении аудиовизуальному переводу на неофилологических факультетах, в частности, интерактивные стратегии и методику преподавания AVT, необходимо исходить из временных ориентиров, а также конкретных задач, поставленных в отдельно взятой вузовской программе. Нашим ключевым постулатом в разработке стратегий преподавания AVT является необходимость достижения учащимися определенного уровня компетенций перед тем, как приступить к аудиовизуальному переводу как таковому. Отсюда время включения настоящего предмета в программу обучения должно быть как можно более поздним, а именно не ранее четвертого года обучения. Вторым весомым замечанием к описываемому предмету является 
длительность периода обучения, которая, по нашим наблюдениям, не может составлять менее, чем 60 академических часов.

Еще раз отметим, что если преподавание AVT не ограничивается лишь видом письменного перевода и, в частности, субтитрированием, то требования к масштабу приобретаемых навыков становятся намного выше. Главной дидактической задачей в этом отношении является формирование у студентов правильных навыков и умений, сосредоточенных в группе языковой, переводческой, коммуникативной, технической и психосоматической компетенций. Основное внимание должно быть уделено формированию у студентов быстроты реакции и речи, психической выносливости, оперативной памяти, семантического билингвизма, правильной дикции, что достигается благодаря соответствующей системе упражнений, отрабатываемой во время занятий по устному переводу. Нелишним будет также замечание относительно необходимости глубокого постижения культуры и национальной специфики стран, в рамках которых будет осуществляться профессиональный AVT. B процессе обучения необходимо также уделить соответствующие время освоению существующих программ по работе с субтитрами, звуком и видеорядом.

В случае полной программы, обучение AVT начинается с ознакомления группы студентов с существующими теоретическими аспектами аудиовизуального перевода, техническими нормами оформления субтитров, программным обеспечением, используемым в процессе оформления, обработки и создания исходных мультимедийных файлов. В дальнейшем, на начальном практическом этапе, происходит освоение основных техник субтитрирования, которое должно осуществляться в рамках практических занятий, причем проверка уровня освоения пройденного материала, в обязательном порядке, реализуется с помощью проект-заданий, за которые каждый учащийся несет индивидуальную ответственность. В случае успешного освоения материала в первой фазе обучения, которая может составить от 20 до 30 академических часов, преподаватель вправе приступить к следующей фазе обучения, предполагающей работу с дублированием.

Оговоримся, что несмотря на факт ангажированности в классическом дубляже профессиональных актеров, это не является, на наш взгляд, помехой в преподавании мастерства оперирования собственным голосом также в случае студентов-лингвистов. Работа с голосом у опытных устных переводчиков является ключевым звеном их профессиональной 
деятельности, причем отсутствие навыков правильной дикции, умений управления своими эмоциями, ответственными за фонетическую артикуляцию, нужно рассматривать как главное препятствие в осуществлении переводческих задач. Отсюда упражнения по записыванию собственного голоса и созданию отдельных аудио-файлов в качестве треков под ранее переведенную мультимедийную продукцию является особенным подспорьем в формировании коммуникативной и переводческой компетенций.

Итак, упражнениям по дублированию видеоряда предшествует ознакомление учащихся с теоретическими и практическими аспектами данного вида AVT, анализ существующей мультимедийной базы, в которой аудиовизуальный перевод использовался в качестве одного из производственных инструментов. Следующим этапом является введение студентов в перспективу работы с программным обеспечением. Практические занятия на основе пройденного материала заключаются в редакции и создании готовых видеофайлов с новым лингвистическим контентом, разработанным в рамках дидактического AVT. Эта работа, с одной стороны, предполагает формирование лингвопереводческой компетенции с учетом интегрированного подхода в переработке языкового материала, с другой - развитие всех остальных вышеописанных компетенций, необходимых в работе AVT. В рамках зачета по пройденному материалу студенты, каждый в отдельности, готовят собственные мультимедийные короткометражные проекты, которые оцениваются преподавателем на соответствие нормам и техническим требованиям AVT.

Можно с уверенностью утверждать, что сегодня любое неофилологическое направление уже не может обойтись без преподавания AVT как наиболее динамично развивающейся дисциплины, без которой область современного перевода просто невозможно представить. Преподавание аудиовизуального перевода, кроме формирования чисто специфических компетенций, требуемых в области AVT, развивает также все остальные умения неофилолога, расширяя масштаб его языковых знаний, а также формируя коммуникативную и переводческую компетенции. 


\title{
БИБЛИОГРАФИЯ
}

Chaume, Frederic. «Synchronization in Dubbing: A Translational Approach». Topics in audiovisual translation, ed. Pilar Orero, John Benjamins Publishing Company, 2004, cc. 35-52.

Díaz Cintas, Jorge, editor. New trends in audiovisual translation. Multilingual Matters, 2009.

Franco, Eliana, Anna Matamala, and Pilar Orero. Voice Over Translation: An Overview. Peter Lang, 2010.

Gambier, Yves. «The position of audiovisual translation studies». The Routledge handbook of translation studies, ed. Millán Carmen, and Francesca Bartrina, Taylor and Francis, 2013.

Garcarz, Michał. Przektad slangu w filmie. Tertium, 2007.

Gorshkova, Vera. Perevod v kino. IGLU, 2006 [Горшкова, Вера. Перевод в кино. ИГЛУ, 2006].

Hendrykowski, Marek. «Z problemów przekładu filmowego». Wielojęzyczność literatury i problemy przektadu artystycznego, red. Edward Balcerzan, Ossolineum, 1984.

Jakobson, Roman. «On Linguistic Aspects of Translation». On translation, ed. Ross Brower, Harvard University Press, 1959.

Kornaukhova, Nataliya. «Audiovizual'nyy perevod v usloviyakh novoy tekhnologicheskoy real'nosti». Nauchnaya diskussiya: voprosy filologii, iskusstvovedeniya $i$ kul'turologii. Internauka, 2016 [Корнаухова, Наталия. «Аудиовизуальный перевод в условиях новой технологической реальности». Научная дискуссия: вопросы филологии, искусствоведения и культурологии. Интернаука, 2016].

Sikora, Iwona. Dubbing filmów animowanych. Oficyna Wydawnicza PWSZ, 2013.

Taylor, Christopher. «Multimodality and audiovisual translation». Handbook of Translation Studies. Vol 4, red. Yves Gambier and Luc Doorslaer, John Benjamins Publishing Company, 2013.

Tomaszkiewicz, Teresa. «Przekład audiowizualny, werbo-wizualny czy intersemiotyczny: różne wymiary tej samej rzeczywistości?». Lingwistyka Stosowana, vol. 3, 2010, cc. 33-44.

Tomaszkiewicz, Teresa. Przektad audiowizualny. Wydawnictwo Naukowe PWN, 2006.

\author{
ИЗБРАННЫЕ АСПЕКТЫ ТЕОРИИ И ПРАКТИКИ \\ ПРЕПОДАВАНИЯ АУДИОВИЗУАЛЬНОГО ПЕРЕВОДА \\ НА ПОЛЬСКИХ НЕОФИЛОЛОГИЧЕСКИХ НАПРАВЛЕНИЯХ
}

Р е 3 ю м е

Аудиовизуальный перевод (анг. audiovisual translation, AVT) это наиболее динамично развивающийся вид перевода современной эпохи. По мнению авторов статьи, популярность этого вида перевода будет только расти. К сожалению, на польских неофилологических направлениях занятия по аудиовизуальному переводу еще не вошли в учебные программы в качестве обязательных предметов. Цель настоящей статьи - привлечь внимание академического сообщества к необходимости включения курсов перевода AVT в учебные программы. В статье рассматриваются тенденции развития AVT и самые популярные техники аудиовизуального перевода: субтитрование и дубляж, которые могут быть успешно использованы в процессе обучения иностранным языкам. Авторы статьи дают рекомендации по способам использования данного типа перевода на занятиях и отвечают на вопрос, какого дидактического эффекта можно достичь благодаря его применению. 
Ключевые слова: аудиовизуальный перевод; преподавание AVT; современные методы обучения иностранным языкам; дидактика на неофилологических направлениях; прикладная лингвистика; дубляж; субтитры.

\section{WYBRANE ZAGADNIENIA \\ Z TEORII I PRAKTYKI NAUCZANIA TŁUMACZENIA AUDIOWIZUALNEGO NA POLSKICH KIERUNKACH NEOFILOLOGICZNYCH}

Streszczenie

Thumaczenie audiowizualne (ang. AVT) jest obecnie najbardziej dynamicznie rozwijającym się rodzajem tłumaczenia. Według autorów niniejszego artykułu ten typ tłumaczeń będzie zyskiwać na popularności. Niestety, w ramach współczesnych polskich neofilologii zajęcia z AVT jeszcze nie weszły do siatki stałych przedmiotów. Artykuł ma za zadanie zwrócić uwagę środowiska akademickiego na konieczność wprowadzenia zajęć z AVT do siatki programowej. W artykule są omawiane najnowsze tendencje teoretyczne rozwoju AVT oraz prezentowane najbardziej popularne techniki tłumaczenia tego typu, które mogą być z powodzeniem wykorzystywane w procesie nauki języków obcych na kierunkach neofilologicznych. Należą do nich przede wszystkim tworzenie napisów oraz dubbing. Artykuł ostatecznie odpowiada na główne pytanie, w jaki sposób można wykorzystać ten rodzaj tłumaczenia na zajęciach i jakie efekty glottodydaktyczne można w ten sposób osiągnąć.

Słowa kluczowe: thumaczenie audiowizualne; nauczanie AVT; nowoczesne metody nauczania języków obcych; dydaktyka na kierunkach neofilologicznych; lingwistyka stosowana; dubbing; napisy.

\section{SELECTED ISSUES FROM THE THEORY AND PRACTICE OF AUDIOVISUAL TRANSLATION TEACHING IN POLISH MODERN LANGUAGE FACULTIES}

\section{Sum mary}

Audiovisual translation (AVT) is the most dynamically developing kind of translation of the modern era. According to the authors of this article, the popularity of this type of translation will only increase. Unfortunately, within the framework of contemporary Polish modern language faculties, classes in audiovisual translation have not yet entered the curricula as obligatory subjects. The aim of this article is to draw the academic community's attention to the necessity of introducing AVT translation classes into the curricula of modern language faculties, such as applied linguistics, translatology and contemporary linguistics. The article discusses the latest theoretical trends in AVT and presents the most popular types of translation of this type, which can be successfully used in the process of learning foreign languages in neophilological fields. These include, above all, subtitling and dubbing. The article ultimately raises the main question of how this type of translation can be used in class and what glottodidactic effects can be achieved in this way.

Key words: audiovisual translation; AVT teaching; modern language teaching methods; modern language education; applied linguistics; dubbing; subtitling. 